\title{
FACEBOOK for CoP of Researchers: Identifying the Needs and Evaluating the Compatibility
}

\author{
Sami Miniaoui', Mohanad Halaweh²
}

\begin{abstract}
Communities of practice (CoPs) are increasingly capturing the interest of many fields such as business companies, education and organizations. Many CoPs were developed for people who have common interest in healthcare, agriculture and environment, and teaching. However, there is lack of COPs dedicated for researchers. This research aims to explore the appropriateness of Facebook (FB) as a platform for serving a CoP of researchers. To achieve this goal, first we identify the needs of CoPs for researchers within UAE context. Consequently, we adopted qualitative research approach to elicit the needs. We applied the grounded theory method to analyze the data. The results of the analysis showed seven main needs: collaboration, debating, awareness/notification, reference management, cross search, customization, tracking, and user orientation. Secondly, we evaluated the compatibility of FB features to the identified needs. Although we found that FB covers most of CoPs needs, there are few needs which are not met successfully so this raised some technical and practical issues, which have been highlighted in the paper.
\end{abstract}

Keywords: Community of practice (cop); cop needs; qualitative research; grounded theory; social networking platforms; facebook.

\footnotetext{
1,2 College of Information Technology, University of Dubai. POBOX: I 4 I43, Deira, Dubai, UAE +97 I4207264 I, +97 I 42072647

Email:sminiaoui@ud.ac.ae, mhalaweh@ud.ac.ae
} 


\section{Introduction}

The concept of community of practice (CoP) was initially introduced by Wenger in the 80th. The origin and primary use of the Communities of practice concept has been in learning theory. However, social scientists have used its versions for various analytical purposes. Lave and Wenger (1991), cognitive anthropologists, defined CoP as a group of people who share a profession, an interest and/or a craft. People can create the group specifically with the aim of gaining knowledge related to their field or it can develop naturally owing to the common interest in a particular area or domain by the members. Lave and Wenger (1991) explained that the process of sharing experiences as well as information with the group enables the members to learn from each other and get an opportunity of developing themselves both professionally and personally.

After a surveying of the literature we found that there are CoPs developed in different domains such as Healthcare Parboosingh (2002); Wild EL (2004); Business Yi (2000) and Education Richardson (2003). However, we depicted a lack of CoPs dedicated to members interested in research activities and particularly working in UAE. Thus, we initiated a whole research project for studying the research activity performed within CoPs that we name "Developing platforms for serving CoP of researchers in UAE". This research is part of this project supported by University of Dubai focusing on providing a CoP of researchers with a platform matching their needs. This project is divided in three main phases:

-Phase I) Identify the needs of researchers: This first stage is a qualitative research focusing mainly on extracting CoPs needs. Data gathering will be performed by conducting interviews with a community of researchers. Then, data analysis will be used to extract generic needs for researchers.

-Phase 2) Implement or use an existing platform for serving CoPs satisfying the identified needs: we are focusing in this second stage on providing the CoP of researchers with a platform embedding a set of tools matching the identified needs.

-Phase 3) Validate the used /implemented platform: this step is the last step of the project focusing on validating the proposed platform by the final users by conducting usability testing evaluating the relevance of the implemented platform compared to the CoP s needs.

The main scope of this paper is to perform the two first stages of the project. We first identify the needs of a CoP of researchers. Second, we choose to adopt FB as a platform matching the identified needs. Using FB in this context is justified by two main reasons:

- FB has key features/functionalities which make it widely used by millions of users for sharing and collaborating.

- Study the adequacy of social tools such as FB to serve as platforms for CoPs and detect their advantages and limitations in the context of CoPs.

The remainder of this paper is organized as follows:

Section 2 is dedicated to literature review. First, we present several researches focusing on providing CoPs with IT tools. Second, we focus on FB as an option to serve CoPs. The usage of FB in several contexts (Education, Libraries and Nursing) is presented to illustrate the wide adoption of FB by heterogeneous CoPs. Then, a detailed presentation of key FB features is presented to explain the core functionalities of this social platform. Section 3 outlines the proposed research methodology. In Section 4 , we present the research findings of the first and the second stages of the project. Section 5, presents the research discussion and implications. Finally, in Section 6 we present the conclusion and future works.

\section{Literature Review IT for CoPs}

According to Wenger (1998) "Communities of practice are groups of people who share a concern or a passion for something they do and learn how to do it better as they interact regularly". In practice, Wenger (2006) explained that a CoP is an environment to share knowledge, exchange, formalize and hence improve or reify the practice which raises the interest of many communities (e.g. companies, education, and organization) Wenger (2006) summarizes the advantages of a CoP into 4 main points as follows: I) CoP helps practitioners to handle the collective responsibility to manage their knowledge (creation, sharing, etc) 2) Increase the performance of 
practitioners because they share and learn new practices and they apply them in their department. 3) Reveal tacit and explicit knowledge through conversation and storytelling. 4) CoP offers the possibilities to users to bypass their formal classical structures and connect with people in other departments, even boundaries. In addition, he pointed out that there are main activities that can be performed within a CoP, these are I) interacting across time and space, debate, discuss comment, answer and brainstorm. 2) Publishing: produce, share, and organize resources. 3) Tending: follow up and participate to the evolution of roles, structure, objectives, interest and needs of the CoP.

Using IT for serving CoPs was introduced initially by Wenger (200I). Based on his experience in maintaining and following-up many CoPs in various domains, he considered that technology must support CoP's needs in 3 main aspects: I) Knowledge exchange. 2) Social exchange and conversation. 3) Information and instruction's work. Many approaches were used for extracting CoP needs. Kunzel et. Al. (2007) for example, suggested to observe CoP with different domain of expertise and to report their needs in terms of practices and tools as each domain has specific particularities. In contrast, Daele (2006) explained that the needs of any CoP member are quite similar to the needs of any employee for his own professional development process. He came up with a model of professional development illustrating clearly that these needs are organized in a cycle starting with experience sharing, analysis, debate/confrontation, creation of new methods and practices, exchange then finally to connect the cycle experiences sharing. Therefore any CoP should include hereabove needs regardless of the domain activities. A recent European project, called PALETTE, followed both approaches to develop a generic CoP needs which represent three domains including teaching, management and engineering. As a result, four common needs were extracted Charlier et. Al. (2007):

- Support participation of CoP members: this need is mainly to communicate with the web, exchange knowledge experience, debate about issues and solution, negotiate, and meet physically or virtually through IT tools.

- Constitute common resource for the CoP: this need is also called by Wenger (1998) "shared repertoire" which constitutes the knowledge capital of the CoP. It is effectively the domain of expertise, the common knowledge they mine and enrich. In other words it is the history of the CoP.

- Support commitment: allow user to formulate their ideas clearly, share it, tune it and refine it based on the general objective of the CoP.

- Support realization of activities: it represents the need for organizing CoP activities, task's repartition, creating a common work place for performing the activities of the CoPs in which they can interact, find resources, edit and collaborate.

Although we value PALETTE project outcomes Charlier et. al. (2007), we argue that the needs generated by PALETTE were too generic Kunzel et. al. (2007). For example, activities related to CoPs for healthcare, sport or environment are different from each other. Obviously, each CoP has its own characteristics and each domain has its particular activities.

In this research, we focus on developing CoP of researchers within UAE and we follow the approach proposed by Kunzel et. al. (2007) and Daele (2006) for extracting CoP needs. The main differences between PALETTE project and our research can be summarized in the following factors:

I) Heterogeneity of CoP domains: the sample of CoP members in PALLETE project were from different domains (teaching, management, Engineering). However, our CoP members have single domain of activities which fall in academic research.

2) Cultural and Geographical: PALETTE project was developed for CoP members working in Europe. In contrast, our research focuses on academic researchers who live and work in UAE universities.

On the other hand, we depicted the emergence of platforms providing an integrated view of many tools. We distinguish here two main categories: I) social platforms (Facebook, myspace, $\mathrm{Hi5}$ ) and 2) widget-holder platforms (Netvibes, igoogle ). Indeed, these platforms are providing the possibility to integrate a set of tools in a unique workspace either by using the widget technology (Van Kesteren and Caceres 2007) or by implementing a dedicated API (application programming interface) for each tool separately in order to integrate it. More specifically, 
social platforms are providing an interesting option since they are widely adopted by millions of people. Indeed, the users are subscribing to these platforms not only for socializing but also for sharing content, participating, scheduling events and doing a set of other activities. In addition, these platforms are offering a wide range of tools that users can use and can also choose from a long list of tools developed by other users without any integrating issue. Thus, the option for reusing these existing platforms for serving CoPs rather than implementing platforms from scratch with all related integration issues previously presented.

\section{Several contexts of use of FB}

Many researchers addressed the potential use of Facebook (FB) in several sectors and fields. For example, in Education, Mazer, et. al. (2008) found that students believed using FB would produce "higher levels of motivation and affective learning and a more positive classroom environment". Kayri and Çakır (2010) suggested that FB might be used as an effective learning environment. They conducted empirical study to examine the educational perception of students about FB. The study showed that that those who spent much time on $\mathrm{FB}$ perceived $\mathrm{FB}$ as an educational tool. Muñoz, and Towner (2009) highlighted a number of unique features that make using FB suitable to teacher in Education. For example, FB includes bulletin boards, instant messaging, email, and the ability to post videos and pictures. Most notably, anyone can post information and collaborate within the system. In addition, FB has opened up development of downloadable applications, which can further supplement the educational functions of FB. They stated that although some may consider these technological tools similar to those found in courseware programs (e.g. blackboard, moodle, etc.), the ability and ease with which instructor or student can upload photo and videos, the frequent and seamless updates and maintenance, the large space with $1024 \mathrm{MB}$ limit on videos, and the compatibility with a wide variety of web browsers are superior to some courseware options. They said FB also increases both teacher-student and student-student interaction in the form of web-based communication. FB helps instructors connect with their students about assignments, upcoming events, useful links, and samples of work outside of the classroom. Students can use FB to contact classmates about questions regarding class assignments or examinations as well as collaborating on assignments and group projects in an online environment.
Tynes (2007) highlighted the psychosocial benefits of social network websites, which includes the facilitation of identity exploration, provision of social cognitive skills such as perspective taking, and to fulfill the need for social support, intimacy and autonomy. The "social spaces" available to people can enable a more personalized experience for learning in an online environment. This support from instant messaging, wikis, blogs, discussion boards, and other Web 2.0 facilities can complement what is taught in a traditional classroom setting.

Also FB was used in libraries field. For example, a case study was conducted by Seckor (2005) to assess the use of FB among librarians in London School of Economics and Political Science. She found that many librarians have joined FB for purely social reasons but the application can overlap into the professional world for the promotion of library related events. She noted that FB has a number of related tools, such as search tools COPAC (Copac: the UK and Irish Academic and National Library catalogue (Copac, 2008) and JSTOR (short for Journal Storage is a United States-based online system for archiving academic journals - (Jstor, 2008), as well as "various tools that allow virtual bookshelves or resource lists to be shared with others" Seckor (2005).

Amerson (20II) advocates the use of FB as a tool for nursing education Research. According to Walton (2009), social networks have the potential to be used for recruitment or data collection. A researcher might search for a specific population of participants via FB, such as a group of people with a chronic disease. People living with this disease may be restricted to their homes but can contact with the outside world through FB. It would provide access to a previously non accessible population. Amerson (20II), for example, used FB to locate previous nursing students and invite them to participate in a qualitative research study. He used FB to contact graduated students from different geographical areas. He found that FB can be used as a locator for connecting with previous students as research study participants. However, Amerson's study did not address the functionality and features of FB to evaluate its applicability for communities of researchers. He just found that FB facilitates collecting data from research participants located in different geographical location. 


\section{Functionalities of Facebook}

Facebook is a social network service and website. Users may create a personal profile then build their network of contracts by adding other users as friends. They can exchange messages in private or in public, receive/send automatic notifications when they update their profile or post a link, photo or a video. Furthermore, users may join common interest user groups, school, a company or any religious, political, cultural community. We depicted a set of commonly used features that we will present in follow:

-Wall: The Wall is a place where users post and share content. Users can follow a stream of updates from friends' wall and pages she/he follows. This feature is called news feed and it is posted by FB in the default home page view. Wall can be used to share content at three levels: Sharing content with a broad audience, sharing content with a small group of friends and Sharing content with an individual.

-Group: Users can create their own group, set its name, invite members and select the privacy settings of this group. As group administrator it is possible to set up a group which requires his approval to let people join. Administrators can also block specific people from joining a group.

-Events: Users can create an event and invite people to the event. Events provide an overview of what's going on around user. User can respond to open events or events she/he is been invited to. Event has a time and may be a place. Event can be Public (i.e. anyone can see the event and its associated content and RSVP) or Private (i.e. by invitation only and event can't be found in search result). -Message: users can read and create private messages with selected users on FB. User can attach photo, video and links to the message.

-Sharing Content: FB provides publisher facility. The publisher is text box where users can create and share various contents (e.g. photos, video, and hyperlinks). The Publisher allows users to select a privacy setting for every post they make. Users are able to choose who will be able to see their post, from everyone, to Friends, to Friends of Friends.

-Search: It is facility that allows FB users to search for people and their content. Search can be broaden to "Posts by Everyone" or "Post by Friends". User can control who can find them and also what content can be seen and used. Currently, FB user can only search for content that has been posted in the last 30 days.

-Network: FB user can join multiple networks. User will have to choose one to be your primary network. The primary network should be whichever network user feels most connected with. The user primary network will appear next to name, and will influence which search results user see first. User can change his/here primary network. The user also can join up to five networks. However certain networks require authenticated email address validation (e.g. college and/or work network). User can have no network at all. Also user may leave a network and in this case the user will no longer be able to see the profiles of non-friends there. It also means that user will be removed from all groups and events that she/ he have joined and created on that network

-Notification: User can send and receive notifications which take different forms (e.g. friend posting message on wall, fiend request, event invitation, etc,). Also FB sends various forms of notification (e.g. suggest friend, update about friends on FB, notify user about friend birthday, etc). Users are notified onsite when log in by having red alert bubble or pop-up real-time notification when someone interact the user (e.g. post on his/here wall). Users can also notified by receiving email and or SMS message. All form of notifications can be controlled by user.

-Like: is a way for users to give positive feedback or to connect with things she/he care about on FB. Users can like content that friends post to give them feedback or like a Page that users want to connect with on FB. Users can also connect to content and Pages through social plug-in or advertisements on and off FB

-FB page: Pages are for organizations, businesses, celebrities, and bands to broadcast great information in an official, public manner to people who choose to connect with them. Similar to profiles, Pages can be enhanced with applications that help the entity communicate and engage with their audiences, and capture new audiences virally through friend recommendations, News Feed stories, FB events, and beyond. 
- Users can create and manage a FB Page for an organization from their personal accounts. Only the official representative of an organization, business, celebrity, or band is permitted to create a Page.

-Connect (Login with FB): Users can use their FB account on several third-party websites and apps. These websites and apps are using the FB Platform. When users connect or login to a website with FB account, it can access information that the user added on FB in order to provide a social and personalized experience on user application the site. The FB Platform Policies restrict how these sites can access and use this information.

-Application and Plug-in: Applications on FB are designed to enhance user experience on the site with engaging games and useful features like Events and Photos. Some applications are built by FB developers, but most applications are built by outside developers who use FB's APIs and abide by FB's Developer Principle and Policies. Applications on FB allow user to do many things. For example: play social games with friends, remember friends' birthdays, share taste in movies, and send gifts to friends.

-Sharing status updates and other content: depending on whom user would like to share with, there are different ways to share content (i.e. photos, videos, links and other application content) on FB:

- Sharing with a broad audience

- Sharing with a small group of friends

- Sharing with an individual

-Tagging: Users can tag friends in her/his FB status and other posts. This feature works when users share content at the top of here/his: home page, profile or friends' profiles. Users can also tag pages, events, groups or applications. Friends being tagged will receive a notification on their profile. They are also notified when someone else comments on the post they are tagged in.

-Instant messaging: Users can chat with one or many friends available online. Users have the choice of staying online or offline and also disable or enable the notification sound.

\section{Research Methodology}

To achieve the first stage of the project, a qualitative research is used to identify the needs of CoP of UAE researchers. We adopted qualitative research as we do not know the needs of researchers within the UAE context and would not presume predefined needs. Therefore applying qualitative research enabled us to explore them and let the participants themselves (i.e. researchers) reveal their needs freely. A total of 7 semistructured interviews were conducted. The participants are professors representing from two UAE universities, mixed gender, active in business and IT research fields, and having age between $30-50$. Based on the literature review, we formulated some questions which are open in nature as shown in Table I. The questions are used as a guide through the interviews. However, we did not rely on these questions only, other emerged questions and ideas during the interview were also considered. The grounded theory method developed by Strauss and Corbin (1990) was also applied to analyze the data as there is a widely held belief that it is a reliable method by which to elicit systems requirements and user needs (Halaweh (20II); Chakraborty and Dehlinger (2009)). For the second stage, we will examine the appropriateness of $\mathrm{FB}$ in matching the identified needs in the first stage. 
(1) How would you like to participate in the activities of a community of practice?

(2) What type of websites would you like to use for sharing experience and information?

(3) What technologies do you use to share your experience? How are they useful? What are the advantages and limitations?

(4) What type of research activities do you wish to perform within community of practice?

(5) What kind of information would you like to exchange with copõ members?

(6) What facilities would you like to have to argue and discuss research topic/ideas? How? Why?

(7) What technology would you like to keep updated? Why?

(8) What facility would you like to have to support social interaction with copđ̃ member? Why?

(9) How would you like to manage knowledge and experience within CoP?

(10) A s a new CoP member, what facilities/instructions would you like to have when you join the community?

(11) How would you broadcast new information/news?

Table I.Interview Questions

\section{Research findings}

Data was analyzed by the authors through applying coding steps (open, axial, selective coding) and constant comparative analysis to validate the concepts and categories. Table 2 shows an example of questions that posed during the interviews to all participants and the response of each one. The result of open coding in this example shows the codes (i.e. represent the significant needs and meaningful ideas in the transcribed data) are underlined. Then, the authors conceptualized the data and assigned names for the codes to develop concepts which represent the CoP needs. Some of these concepts were mentioned explicitly by the participants and some were reflected and interpreted by the authors. As shown in the same example that sharing (e.g. paper, links), debating and commenting (e.g. on raised issues through forums) are one of important requirements of CoP for researchers. We applied the same method of analysis for all questions' responses. Then we grouped related concepts together to form a higher level category and we come up with the 7 categories. These categories are depicted in Figure I. It can be seen from the figure that collaboration is the core category as resulted from the data analysis. It represents the key need of CoP of researchers within UAE. This category includes three sub-categories which are content management, communication and debating. 


\begin{tabular}{|c|c|c|}
\hline & H ow would you like to participate in the activities of a community of practice? & Concepts \\
\hline Participant 1 & $\begin{array}{l}\text { Sharing research paper with other, like if one of the faculty found a good paper he } \\
\text { can post it and comment on it, and there could be a part to summarize the paper to } \\
\text { save our time on reading, so when you access to the paper you will find the } \\
\text { summary there. } \\
\text { There is a tool called delouses to share links, you can favorite your best links then } \\
\text { you can share them, also instead of sharing the links locally you can share them } \\
\text { within the internet and you can create a category of links. It also uses a tag method. } \\
\text { It helps in selecting the related links for cop and can be shared with others. }\end{array}$ & Sharing \\
\hline Participant2 & $\begin{array}{l}\text { might share by giving feedback like the forums, ideas of my own practice, reflect } \\
\text { on some ideas proposed by other, provide example or case li have countered in this } \\
\text { country(e.g. in my teaching, research and many other). }\end{array}$ & Sharing \\
\hline Participant3 & $\begin{array}{l}\text { would like to share any kind of experience, use technologies like forums, blogs, } \\
\text { register in a forum, and send e-mails to partners. }\end{array}$ & Sharing \\
\hline Participant4 & $\begin{array}{l}\text { would like to give more feedback and comment on any raised issues, they are } \\
\text { simple comments to describe and discuss. }\end{array}$ & Commenting \\
\hline Participant5 & $\begin{array}{l}\text { Have ability to propose a topic, discuss and join a topic proposed by other members. } \\
\text { would like to combine my feedback with multimedia technology and use some } \\
\text { tools such as (black bored discussion technique) and forum }\end{array}$ & debating \\
\hline Participant6 & $\begin{array}{l}\text { would like to give more feedback and comment on at any raised issues, they are } \\
\text { simple comments to describe and discuss. }\end{array}$ & Commenting \\
\hline Participant7 & would like to subscribe myself first then share links betw een colleagues. & Sharing \\
\hline
\end{tabular}

Table 2.Sample of data analysis for participants' responses to one question. 


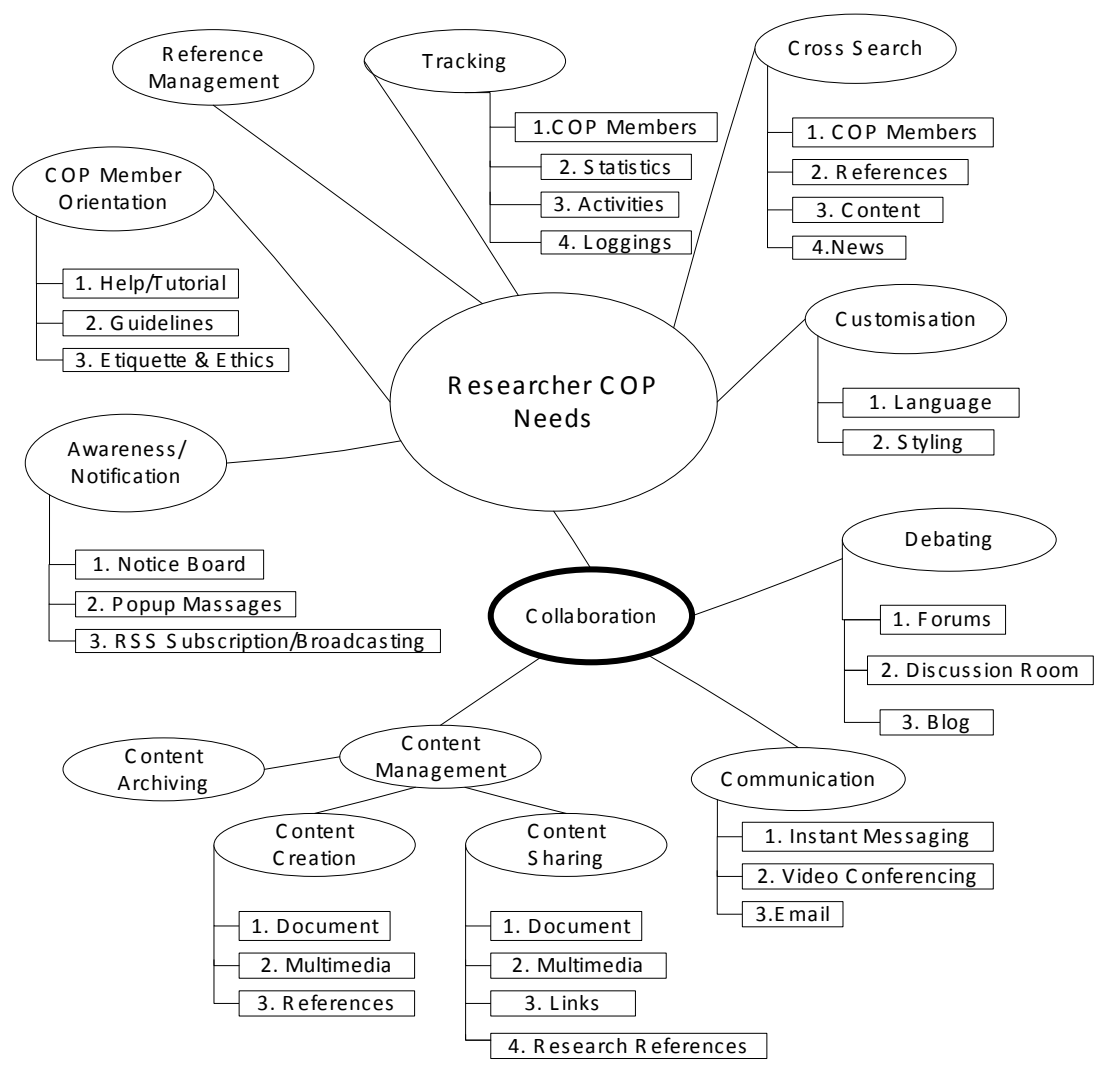

Figure I.CoP needs for UAE researchers identified by Grounded Theory Method.

As follows brief description of each of the CoP needs: Content management is part of the collaboration need and it is further divided into three related needs namely: Content creation, content sharing and content archiving. - Content creation: refers to the ability of creating various types of contents such as text, multimedia (i.e. audio, video, images, etc) and references to books and publications.

- Content sharing: refers to the ability of sharing contents (text, multimedia and references) regardless of whether the content is created locally or imported externally.

- Content archiving: The CoP members wish to capitalize on the CoP information assets. They wish to keep and maintain current and past content .

Communication: is part of the collaboration need. The CoP members wish to have various methods of communication (e.g. instant messaging, video conferencing) that reflects different needs (i.e. time \& location differences).

Debating: is part of the collaboration need. This category refers to the need offormal and informal method of interactive and representational argument. So often, researchers need to discuss a matter of interest or topic. Some researches reflect the need for having the debate openly where anyone can participate in the debate; others highlight the need for having a channel to debate about a matter privately in a chat room for example. Most researchers reflect the need for having technology where they wish to have their own blog where they post a topic and wish to get a comment from other CoP members or visitors.

Awareness/Notification: this category reflects the need for keeping CoP members up to date so that they are informed about research news, conferences and any mater of interest. CoP members wish to post messages where every CoP member and other audience are aware about CoP news. Also, CoP members wish to be notified about external news that matter the CoP.

Reference Management: this category reflects the need for sharing, recording and utilizing central database of references. This need clearly make the CoP researcher different than other previously studied CoP. 
Cross Search: CoP members wish to have a function that allows them to search for any stored content and also to search for CoP members. The function should be simple or advance so different criteria could be used in the search.

CoP Member Orientation: new CoP member should be able to get full information about the CoP such as: how to join and get help; tutorial and guidelines about using the CoP; rules of etiquette and code of practice.

Tracking: this category reflects the ability for monitoring a matter of CoP member interest. Members should be able to seek information about CoP members, get statistical reports, follow CoP member(s) and monitor an activity.
Customization: CoP members should be able to customize the technology to reflect various usability need. Members should be able to change the styling (e.g. colors, fonts, etc.). Using different Languages (e.g. Arabic, English) was one of the main CoP requirements. This need also reflect the cultural and geographical differences.

\section{Evaluation the compatibility of FB functionalities with CoPs needs}

This section explores the suitability of FB functionalities to cover the researchers' CoP needs. The table in follows is illustrating the matching of FB features with CoP's needs.

\begin{tabular}{|c|c|c|c|c|c|c|c|c|c|c|c|c|c|c|c|c|c|c|c|c|c|c|c|}
\hline \multirow{3}{*}{$\begin{array}{l}\text { Needs } \\
\text { FB features }\end{array}$} & \multicolumn{3}{|c|}{$\begin{array}{l}\text { Content } \\
\text { mana- } \\
\text { gement }\end{array}$} & \multicolumn{3}{|c|}{$\begin{array}{l}\text { Comm- } \\
\text { unicatio } \\
\text { n }\end{array}$} & \multicolumn{3}{|c|}{ Debating } & \multicolumn{3}{|c|}{$\begin{array}{l}\text { Awareness } \\
\text { /notifi- } \\
\text { cation }\end{array}$} & \multirow[t]{3}{*}{$\begin{array}{l}\text { Refer- } \\
\text { ence } \\
\text { Mana- } \\
\text { gement }\end{array}$} & \multirow[t]{3}{*}{$\begin{array}{l}\text { Cross } \\
\text { Search }\end{array}$} & \multicolumn{3}{|c|}{$\begin{array}{l}\text { CoP } \\
\text { Member } \\
\text { Orient- } \\
\text { ation }\end{array}$} & \multirow{2}{*}{\multicolumn{4}{|c|}{ Tracking }} & \multirow{2}{*}{\multicolumn{2}{|c|}{$\begin{array}{l}\text { Custo- } \\
\text { miza- } \\
\text { tion }\end{array}$}} \\
\hline & \multirow[t]{2}{*}{1} & \multirow[t]{2}{*}{2} & \multirow[t]{2}{*}{3} & \multirow[t]{2}{*}{1} & \multirow[t]{2}{*}{2} & \multirow[t]{2}{*}{3} & \multirow[t]{2}{*}{1} & \multirow[t]{2}{*}{2} & \multirow[t]{2}{*}{3} & \multirow[t]{2}{*}{1} & \multirow[t]{2}{*}{2} & \multirow[t]{2}{*}{3} & & & & & & & & & & & \\
\hline & & & & & & & & & & & & & & & 1 & 2 & 3 & 1 & 2 & 3 & 4 & 1 & 2 \\
\hline Wall & & $\mathrm{x}$ & $\mathrm{x}$ & & & & & & & $\mathrm{x}$ & & & & $\mathrm{x}$ & $\mathrm{x}$ & & & $x$ & & $x$ & & & \\
\hline Events & & & & & & & & & & $\mathrm{x}$ & & & & & & & & & & & & & \\
\hline $\begin{array}{l}\text { Message / } \\
\text { Comment }\end{array}$ & & & & $\mathrm{x}$ & $x$ & $\mathrm{x}$ & $\mathrm{x}$ & $\mathrm{x}$ & $\mathrm{x}$ & $\mathrm{x}$ & & & & & & & & & & & & & \\
\hline Share resources & & $\mathrm{x}$ & $\mathrm{x}$ & & & & $\mathrm{x}$ & $\mathrm{x}$ & & & & & & & & & & & & & & & \\
\hline Content & & $\mathrm{x}$ & $\mathrm{x}$ & & & & $\mathrm{x}$ & $\mathrm{x}$ & $x$ & $\mathrm{x}$ & & & & & & & & & & & & & \\
\hline Search & & & & & & & & & & & & & & $x$ & & & & & & & & & \\
\hline Like & & & & & & & $x$ & $\mathrm{x}$ & $\mathrm{x}$ & & & & & & & & & & & & & & \\
\hline $\begin{array}{l}\text { Application and } \\
\text { Plug-in }\end{array}$ & & & & & & & & & & & & & & & & & & & & & & & \\
\hline $\begin{array}{l}\text { Instant } \\
\text { messaging }\end{array}$ & & & & $x$ & $x$ & $\mathrm{x}$ & $\mathrm{x}$ & & & & & & & & & & & & & & & & \\
\hline note & & $\mathrm{x}$ & $\mathrm{x}$ & & & & $\mathrm{x}$ & $\mathrm{x}$ & $\mathrm{x}$ & & & & & & & & & & & & & & \\
\hline help & & & & & & & & & & & & & & & $\mathrm{x}$ & $\mathrm{x}$ & $\mathrm{x}$ & & & & & & \\
\hline settings & & & & & & & & & & & & & & & & & & & & & & $x$ & $\mathrm{x}$ \\
\hline Inbox messages & & & & & & $x$ & & & & & & & & & & & & & & & & & \\
\hline
\end{tabular}


The hereabove table shows interesting results that we will comment in this section. We can divide the coverage of CoPs needs by the FB features into 3 main classes as follows:

\section{I-Needs covered by exactly one FB feature:}

Features such as cross search, customization, CoP orientation and awareness needs are covered by respectively search, settings, help, and events. Such features should be integrated to any further platform that serves CoPs. It is relevant to mention at this level a comment regarding the search feature. Indeed, the cross search needed in the context of CoPs is targeting mainly: - Search for heterogeneous resources (links, images, video, text, blog post, forum discussion, note, etc)

- Search across many tools (documents posted or created by several tools of the CoP platform).

However, this option is not provided by FB search. Indeed, FB search feature is only allowing users to search for users or groups but neither for resources (links, images, video, text, blog post, forum discussion, note, etc) nor across many FB applications used by the users. This limitation is mainly due to the absence of resources' indexing in FB which is very crucial in the context of CoPs. Thus, in any further development of platforms serving CoPs, we should integrate an option for resources indexing in order to allow the search of different resources and across many applications. In this context, Dublin Core metadata standard DCMI (2010) would be an interesting option for the uniform tagging of the resources.

\section{2-Needs covered by many FB features:}

Features such as comment, wall, instant messaging, communication and note are covering many CoPs needs such as communication, awareness, debating, and content management. Integrating these features is necessary in any platform even though they are providing overlapping. Their availability in the CoP platform gives more flexibility to users. For example, some users are more familiar with instant messaging so they will use it for debating rather than commenting.

\section{3-Needs not covered by any FB features:}

Features such as awareness/notification (Popup message, RSS subscription), Content management (archiving) and Reference management are needs that are not covered by any FB feature.

-Awareness is one of the most successful features in FB. It keeps any user updated regarding the activity of a friend, a page or a group (posted links, images, video, etc) by grouping this information on his Wall. This awareness mechanism offered by FB is quite similar to the notification option provided by syndication systems such as RSS feeds. In fact RSS feeds are mainly providing subscribed users with updates of websites or specific rubric of the website (news, new items added in a specific webpage, etc). So we can consider that this awareness need (RSS subscription) is met by the FB News feeds feature. On the other hand, the popup message need is mainly intended to keep the user updated about new resources, users, deadlines and here also the FB News feeds feature is providing a similar option by displaying (new received messages, new users, deadlines for birthdays or events) .

-Content archiving need: this concept is illustrating the history or knowledge capital of the CoP. According to Wenger et. al. (2002), any CoP emerges, evolves and normally after a certain time, users have to organize the resources to make the CoP workspace up to date with new data. By archiving, users can search for previous documents and retrieve them on demand. This process is part of resources management where users produce, share, archive then search for the content and it's mainly possible due to the indexing of resources which is completely missing in FB. It would be relevant that indexing interface could be developed to index or tag resources in order to make it searchable later.

-Reference management need: it is a very specific researchers' need. References are a set of information describing a conference, a journal paper or a book and following a specific format used in references. Default features in FB are not integrating such specific tool for reference management. However, the plug-in feature of FB could be a good option to cover this need. In fact, FB is providing a set of API (application programming interface) for applications focusing on various domains: Education Business, Games, etc. These applications can be included to the FB platform by simply accepting to 
share the FB login information with these applications and hence provide a single sign on. Finding an application for reference management requires either finding an application in the list provided by FB or developing an API of an existing reference management application especially for FB which is hard to fulfill. Furthermore, no many standard applications such as Endnote' are proposing dedicated API for FB.

-Tracking need: especially, statistics and loggings needs are not covered by any FB feature. In the context of CoP, these needs provide any user with logging information of other CoP members as well as statistical reports reflecting their contribution to several activities. This logging information is not provided by any FB Feature as $F B$ is the unique owner of this sensitive data and follows in this context a strict privacy policy to protect its users.

\section{Discussion}

The first stage of the project aimed to identify the CoP needs of researchers within UAE. The result of the qualitative research revealed seven categories: collaboration, debating, awareness/notification, reference management, cross search, customization, tracking, and user orientation. These categories are mainly functional which are required for any CoP of researcher as most of these needs represent and support the main research activities. However, the empirical data also showed that there are some cultural issues which are relevant particularly to the UAE context such as language, weather and gender segregation in education. Some of the participants showed the need to have an option to change the language to Arabic. This is applied to the platform menus and interfaces, the created contents, and the search options.

The other issue is related to the weather of UAE that is very hot especially in summer where the temperature sometimes reaches to $50 \mathrm{C}$. The geographical and weather positions of UAE make the mobility of people unfavorable during the summer time. This motivates participants to have a platform where they can collaborate online without the need to meet face to face.
In addition, some participants argued that there is justifiable need for CoP of researchers in UAE for gender mix constraint. The UAE governmental educational system segregates students based on gender at universities and this also requires isolating the professors. Females cannot easily meet males face to face for religious and cultural reasons therefore this limits the research collaboration and discussion liberally. However, the last two issues are apart from the platform and its functionality.

In the second stage, we investigated the use of $F B$ as a platform for a CoP of researchers. We can mention at this stage that FB covers most of the CoPs needs. Some needs such as RSS feeds and popup messages are not explicitly covered by FB platform but implicitly some reserved $F B$ features such as news feeds are fitting them. However, some other needs such as archiving, tracking and reference management are not covered by any FB feature. Especially for reference management which is a significant need for researchers, we propose using FB plug-in application to cover it.

\section{Conclusion}

This paper has made a contribution by identifying the need of CoP of researchers and studying the appropriateness of $F B$ as a platform for CoP of researchers, which is up to our knowledge the first work in this domain. Although this work focused on exploring the CoP needs in the UAE context, it is obvious that the identified needs (e.g. content management, communication, reference management and awareness/notification) can be applicable to CoP of researchers in any other research community rather than $U A E$. We found that reusing existing platforms such as FB, which covered most of the needs, might be considered as a valuable alternative option instead of developing dedicated platform from scratch.

In our future work we plan to add plug-in application for reference management to $F B$ then conduct a usability testing of this platform by a community of researchers. The result of the usability testing will guide us to affirm that FB can be used as a platform for CoPs.

\footnotetext{
I http://www.endnote.com
} 


\section{References}

AMERSON, R. (201I). Facebook: A Tool for Nursing Education Research, Journal of Nursing Education.

CHARLIER, B., Boukottaya, A., Daele, A., Deschryver, N., El Helou, S., Naudet, Y. (2007). Designing services for CoPs : first results of the PALETTE project. TEL-CoPs'07: 2nd International Workshop on Building Technology Enhanced Learning Solutions for Communities of Practice, Crete, Greece.

CHAKRABORTY, S., Dehlinger, J. (2009). Applying the Grounded Theory Method to Derive Enterprise System Requirements. 10th ACIS International Conference on Software Engineering, Artificial Intelligences. Networking and Parallel/Distributed Computing, Daegu, Korea.

DAELE, A. (2006). A model for representing professional development through the participation in a virtual CoP: uses for developing enhanced services. TEL-CoPs: First international workshop on building technology enhanced learning solutions for Communities of practice, Crete Greece.

DAELE, A., Erpicum, M. , Esnault, L., Pironet, F., Platteaux, H., Vandeput, E. (2006). An example of Participatory design methodology in a project which aims at developing individual and organisational learning in Communities of practice. TEL-CoPs: First international workshop on building technology enhanced learning solutions for Communities of practice, Crete Greece.

DCMI.(2010). Dublin Core Metadata Initiative. http:// dublincore.org/documents/demi-terms[January 2008]

HALAWEH, M. (20II). Using Grounded Theory as a Supportive Technique for System Requirements Analysis. The Sixth International Conference on Systems, St. Maarten, The Netherlands Antilles.

HALAWEH, M., Al Mourad, B., Miniaoui, S. (20II). Identifying the needs of community of practice (CoP) for researchers within UAE. European, Mediterranean \& Middle Eastern Conference on Information Systems 2011 (EMCIS20II), Athens, Greece.
KAYRI, M., Çakır, Ö. (2010). An Applied Study on Educational Use Of Facebook As A Web 2.0 Tool: The Sample Lesson Of Computer networks And Communication. International Journal of Computer Science \& Information Technology (IJCSIT), 2(4).

KüNZEL, M., Charlier, B., Daele, A. (2007). Modelling activity and development of communities of practices. EIAH07 Conference, Lausanne, Switzerland.

LAVE, J., Wenger, E. (199I).Situated Learning: Legitimate Peripheral Participation. Cambridge University Press.

MAZER, J. P., Murphy, R.E., Simonds, C.J. (2008). I'll see you on 'Facebook': The Effects of Computer-Mediated Teacher Self-Disclosure on Student Motivation, Affective Learning, and Classroom Climate. Communication Education, 56(I), I-I7 .http://dx.doi.org//0.1080/036345206010097/0.[ I7 Feb 2007]

MUÑOZ, C., Towner, T. (2009 ). Opening Facebook: How to Use Facebook in the College Classroom. Society for Information Technology and Teacher Education conference in Charleston, South Carolina.

PARBOOSINGH, J.T. (2006). Physician communities of practice: where learning and practice are inseparable. Journal of Continuing Education in the Health Professions, 22, 230-236.

RICHARDSON, B., Cooper, N. (2003). Developing a virtual interdisciplinary research community in higher education. Journal of Inter-professional Care, 17,173-182. SECKOR, J. (2005). Case Study 5: Libraries and Facebook. London School of Economics and Political Science, http:// clt.Ise.ac.uk/Projects/Case_Study_Five_report.pdf.

STRAUSS, A.L., Corbin, J. (1990). Basics of qualitative research: Grounded theory procedures and techniques. Sage Publications.

TYNES, B. M. (2007). Internet Safety Gone Wild?. Journal of Adolescent Research. 22(6), http://jar.sagepub.com/cgi/ content/abstract/22/6/575. 
VAN KESTEREN, A., Caceres, M. Eds. (2007).Widgets I.0. W3C Working Recommendation.

www.w3.org/TR/widgets [May 30, 2007]

WALTON, N. (2009). Facebook and research, Web blog post. http://open.salon.com/blog/ researchethics/2009/06/14/facebook_and_research [JUNE I4, 2009]

WENGER, E. (1998). Communities of Practice: Learning, Meaning, and Identity. Cambridge University Press.

WENGER, E. (200I). Supporting communities of practice: a survey of community-oriented technologies. Report of the Council of CIOs of the US Federal Government.

WENGER, E. (2006). Communities of practice: a brief introduction. http://www.ewenger.com/theory/ communities_of_practice_intro.htm [June 2006]

WENGER, E., McDermott R., Synder, W. (2002). Cultivating Communities of Practice. Harvard Business School Press, Boston.

WILD, E.L., Richmond, P.A, de merode, L., Smith, J.D. (2004). All Kids Count Connections: a community of practice on integrating child health information systems. Journal of Public Health Management Practice, S6I-5.

YI, J.Q. (2000). Supporting business by facilitating organizational learning and knowledge creation in the MOT community of practice (CoP). Indiana University, Bloomington. 
J. Technol. Manag. Innov. 20II,Volume 6, Issue 4 